\title{
Birth weight, body mass index and asthma in young adults
}

\author{
Seif O Shaheen, Jonathan A C Sterne, Scott M Montgomery, Hossain Azima
}

\begin{abstract}
Background-Impaired fetal growth may be a risk factor for asthma although evidence in children is conflicting and there are few data in adults. Little is known about risk factors which may influence asthma in late childhood or early adult life. Whilst there are clues that fatness may be important, this has been little studied in young adults. The relations between birth weight and childhood and adult anthropometry and asthma, wheeze, hayfever, and eczema were investigated in a nationally representative sample of young British adults.

Methods-A total of 8960 individuals from the 1970 British Cohort Study (BCS70) were studied. They had recently responded to a questionnaire at 26 years of age in which they were asked whether they had suffered from asthma, wheeze, hayfever, and eczema in the previous 12 months. Adult body mass index (BMI) was calculated from reported height and weight.
\end{abstract}

Results-The prevalence of asthma at 26 years fell with increasing birth weight. After controlling for potential confounding factors, the odds ratio comparing the lowest birth weight group ( $<2 \mathrm{~kg}$ ) with the modal group (3-3.5 kg) was 1.99 (95\% CI 0.96 to 4.12 ). The prevalence of asthma increased with increasing adult BMI. After controlling for birth weight and other confounders, the odds ratio comparing highest with lowest quintile was $1.72(95 \%$ CI 1.29 to 2.29$)$. The association between fatness and asthma was stronger in women; odds ratios comparing overweight women (BMI 25-29.99) and obese women $(B M I \geqslant 30)$ with those of normal weight (BMI <25) were 1.51 (95\% CI 1.11 to 2.06$)$ and $1.84(95 \%$ CI 1.19 to 2.84$)$, respectively. The BMI at 10 years was not related to adult asthma. Similar associations with birth weight and adult BMI were present for wheeze but not for hayfever or eczema.

Conclusions-Impaired fetal growth and adult fatness are risk factors for adult asthma.

(Thorax 1999;54:396-402)

Keywords: adult asthma; body mass index; birth weight

Dr S Shaheen.

Received 27 July 1998

Returned to author

16 September 1998

Revised manuscript received

16 December 1998

Accepted for publication

16 December 1998

There is currently interest in the role of fetal growth patterns in the inception of asthma. ${ }^{1} \mathrm{~A}$ few studies have found a relation between lower birth weight and asthma in children, ${ }^{23}$ but most have not. ${ }^{4-7}$ In contrast, two very large studies of male conscripts have found clear evidence for an association. ${ }^{8} 9$ There are few data, however, on the relation between lower birth weight and asthma beyond late adolescence because of the paucity of reliable data on individuals followed prospectively from birth into adult life.

Asthma in childhood may persist or remit and asthma may develop de novo in adult life. It therefore seems likely that these different patterns of disease may be determined in part by risk factors in later childhood or early adulthood which might add to or modify the effects of the prenatal environment. There are clues that obesity may be important. In Britain the rise in asthma in children and in adults has been accompanied by an epidemic increase in the prevalence of overweight and obesity. ${ }^{10-15} \mathrm{~A}$ positive association between body mass index (BMI) and asthma and persistent wheeze has been reported in children ${ }^{2}{ }^{16}$ and surveys of predominantly older adults have found that overweight and obese individuals, as defined by $\mathrm{BMI}$, were more likely than those of normal weight to report a history of asthma and bronchitis. ${ }^{18}{ }^{19}$ However, it may be difficult to distinguish asthma from smoking related obstructive lung disease in older adults. Data on the association between fatness and asthma in young adults are lacking.

Cohorts followed from birth to adult life provide an opportunity to examine the relative importance of risk factors in early versus later life and the interplay between them for chronic diseases such as asthma. We investigated the relations between birth weight and childhood and adult anthropometry and adult asthma and wheeze in individuals from the 1970 British national birth cohort who were recently followed up at 26 years of age. In particular, we have examined whether impaired fetal growth and subsequent obesity are risk factors. In order to understand whether associations were common to other atopic diseases or were specific to asthma, we also investigated how these factors related to hayfever and eczema.

\section{Methods}

The 1970 British Cohort Study (BCS70) is an ongoing follow up study of all individuals born between 5 and 11 April 1970 who are still living in Britain (excluding Northern Ireland).
Data were collected from the cohort at birth, 5, 10,16 and, most recently, at 26 years of age. Details of the cohort have been described elsewhere. ${ }^{20-22}$ 
26 YEAR FOLLOW UP

A postal survey of all BCS70 cohort members for whom a current address was available was conducted in 1996. The total target population was estimated as 16500 and questionnaires were mailed to the 13500 cohort members who could be traced. Most of the addresses were held by the Social Statistics Research Unit (SSRU) at City University which has maintained contact with the cohort. In an attempt to minimise response bias, additional valid addresses were obtained through a letter forwarding service offered by the Driver and Vehicle Licensing Agency, Swansea, UK and through tracing conducted by the SSRU using earlier BCS70 records, telephone enquiries, and address records held by the Family Health Service Authorities in England and Wales. Of those individuals who were traced, a total of 8960 questionnaires were returned. The expected proportion of men in the target population was $51.1 \%$; of the respondents $45.6 \%$ were men. ${ }^{22}$ The proportion of individuals who were from non-manual social classes at birth was $65.9 \%$ amongst respondents compared with $70.5 \%$ in the original birth cohort. The social class distribution of those individuals with complete data who were included in the main analyses was representative of all respondents.

OUTCOMES

The questionnaire asked whether the subject had suffered from asthma, wheezing with a cold or flu, hayfever, or eczema in the previous 12 months. These were our primary outcomes of interest. Individuals who had suffered from asthma, wheeze or wheezy bronchitis in the previous 12 months at 10 years, according to information from the mother and from a medical examination, were classified as having had "asthma/wheeze" at the age of 10 .

ANTHROPOMETRY

Birth weight was recorded by midwives from maternity records. We categorised it into six groups at intervals of $0.5 \mathrm{~kg}$. At 10 years of age height, weight, and head circumference were measured and at 26 years of age subjects were asked to report their height and weight. Body mass index (weight/height ${ }^{2}$ ) at 10 and 26 years was calculated and, for comparability with other studies, we also defined subjects as "overweight" (BMI 25-29.99) and "obese" $(\mathrm{BMI} \geqslant 30)$ at 26 years of age according to UK definitions. ${ }^{23}$ Anthropometric measures during childhood and at age 26 were divided into quintiles, separately for men and women.

\section{CONFOUNDERS}

Information was available from birth and follow up at five and 10 years on known risk factors for atopic disease and other personal and socioeconomic factors which might be potential confounders. "Key" confounders, which had previously been identified as risk factors for atopic disease in analysis of this cohort at 16 years ${ }^{24}{ }^{25}$ were sex, father's social class at birth (classified in six groups ${ }^{26}$ ), mother's age, mother's smoking history in pregnancy (whether smoked throughout pregnancy and amount smoked), duration of breast feeding (never, <1, 1-3, >3 months), and number of older and younger children in the household. Information was also available on additional potential confounders including gestational age, smoking history of mother and father during childhood, region of birth, type and tenure of accommodation, whether damp present in accommodation in childhood, household amenities (use of indoor lavatory, bathroom and hot water), household goods (telephone and fridge), social rating of neighbourhood (urban/rural and poor/well off), and reported height and weight of the mother and father (from which we calculated BMI). A "family history of atopy" was defined by the presence of hayfever, eczema, or asthma in either parent or any sibling. At 26 years of age subjects were asked about their smoking history (never, ex and current ( $\leqslant 10$ and $>10$ cigarettes per day)) and educational qualifications which were defined as the highest attained (none, CSE or lower, O level, A level, degree or higher).

ANALYSIS OF DATA

All analyses were done using the statistical package Stata. Associations were examined using logistic regression. In the main analyses (presented in the tables) we controlled for the "key" confounders listed above (with the exception of maternal age and duration of breast feeding which were not associated with any outcome at 26 years) and for educational attainment and smoking history at 26 years. Birth weight and adult BMI were controlled for each other as birth weight tends to be positively associated with subsequent obesity. ${ }^{27}$ Adult BMI was controlled for adult height as it has been proposed that BMI alone may not adequately describe the relation of body composition and body size to health outcomes. ${ }^{28}$ In subsidiary analyses we also controlled, in those individuals with complete information, for those additional potential confounders listed above, for whom the $\mathrm{p}$ value for the univariate association with an outcome was $<0.1$. In the analyses of asthma and wheeze we looked for interactions between the effects of BMI and sex, birth weight, adult smoking, family history of atopic disease and parental anthropometry.

\section{Results}

Table 1 shows the prevalence of asthma, wheeze, hayfever, and eczema in the previous 12 months in all men and women who responded at 26 years, and the distribution of overweight and obesity. The prevalence of asthma, wheeze, and eczema was higher in women than in men. The proportion of men and women who were overweight or obese was $35 \%$ and $22 \%$, respectively.

There were 6420 individuals with complete data on anthropometry and confounding factors. We examined the relations of birth weight and adult anthropometry to asthma and wheeze (table 2) and to hayfever and eczema (table 3) after controlling for key potential confounding factors. For birth weight, social 
Table 1 Prevalence of asthma, wheeze, hayfever, and eczema in the previous 12 months and overweight and obesity at age 26 years

\begin{tabular}{lll}
\hline & Men (disease/total) & $\begin{array}{l}\text { Women } \\
\text { (disease/total) }\end{array}$ \\
\hline Asthma & $277 / 4078(6.8 \%)$ & $437 / 4881(9.0 \%)$ \\
Wheeze & $483 / 4078(11.8 \%)$ & $739 / 4882(15.1 \%)$ \\
Hayfever & $837 / 4078(20.5 \%)$ & $1010 / 4882(20.7 \%)$ \\
Eczema & $333 / 4078(8.2 \%)$ & $699 / 4882(14.3 \%)$ \\
Overweight $\quad(B M I 25-29.99)$ & $1142 / 3987(28.6 \%)$ & $741 / 4729(15.7 \%)$ \\
$\quad$ Obese (BMI $\geqslant 30)$ & $236 / 3987(5.9 \%)$ & $302 / 4729(6.4 \%)$ \\
\hline
\end{tabular}

class at birth, and educational attainment at 26 years we used the modal group as the baseline because of small numbers in the lowest group. The prevalence of asthma and wheeze fell with increasing birth weight. This effect became stronger on controlling additionally for gestational age (odds ratio for asthma compar- ing $<2 \mathrm{~kg}$ with $3-3.5 \mathrm{~kg}, 3.13$ (95\% CI 1.31 to 7.46)). There was no clear association between birth weight and hayfever although the prevalence of hayfever was higher in individuals in the highest birth weight group ( $>4 \mathrm{~kg}$ ) compared with the modal group. Birth weight was unrelated to eczema.

The prevalence of asthma and wheeze rose with increasing adult BMI and was particularly raised in the highest quintile. Controlling for birth weight increased the estimated effect of BMI, as birth weight was positively associated with adult BMI. A similarly strong effect of $\mathrm{BMI}$ on asthma was seen if it was analysed as a continuous variable and if height was omitted from the regression model. BMI was not significantly related to hayfever or eczema. The relations of BMI to asthma and wheeze were little altered by controlling for additional

Table 2 Association of asthma and wheeze in the previous 12 months at 26 years with early life risk factors and adult characteristics. Odds ratios are controlled for other factors in the table

\begin{tabular}{|c|c|c|c|c|c|}
\hline & \multirow[b]{2}{*}{$n(\%)$} & \multicolumn{2}{|l|}{ Asthma } & \multicolumn{2}{|l|}{ Wheeze } \\
\hline & & OR $(95 \% C I)$ & $p^{1}$ & OR $(95 \% C I)$ & $p^{1}$ \\
\hline \multicolumn{6}{|l|}{ Sex } \\
\hline$M$ & $2892(45.0)$ & 1 & \multirow[t]{2}{*}{0.051} & 1 & \multirow[t]{2}{*}{$<0.001$} \\
\hline $\mathrm{F}$ & $3528(55.0)$ & $1.21(1.00$ to 1.46$)$ & & $1.33(1.14$ to 1.55$)$ & \\
\hline \multicolumn{6}{|c|}{ Maternal smoking in pregnancy } \\
\hline No & $2887(45.0)$ & 1 & \multirow[t]{6}{*}{0.669} & 1 & \multirow[t]{6}{*}{0.708} \\
\hline Stopped prior & $861(13.4)$ & $1.03(0.78$ to 1.37$)$ & & $1.18(0.94$ to 1.47$)$ & \\
\hline Stopped during & $305(4.8)$ & $0.97(0.63$ to 1.50$)$ & & $0.90(0.63$ to 1.30$)$ & \\
\hline$<5 /$ day & $453(7.1)$ & $1.09(0.77$ to 1.56$)$ & & $0.87(0.64$ to 1.19$)$ & \\
\hline 5-14/day & $1245(19.4)$ & $1.04(0.81$ to 1.34$)$ & & $1.15(0.94$ to 1.40$)$ & \\
\hline$\geqslant 15 /$ day & $669(10.4)$ & $0.81(0.58$ to 1.14$)$ & & $0.99(0.77$ to 1.27$)$ & \\
\hline \multicolumn{6}{|l|}{ Birth weight $(\mathrm{kg})$} \\
\hline$<2$ & $66(1.0)$ & 1.99 (0.96 to 4.12$)$ & \multirow{6}{*}{0.004} & 1.53 (0.80 to 2.92$)$ & \multirow{6}{*}{0.001} \\
\hline $2-2.5$ & $263(4.1)$ & $1.33(0.86$ to 2.06$)$ & & $1.02(0.70$ to 1.49$)$ & \\
\hline $2.5-3$ & $1194(18.6)$ & $1.21(0.95$ to 1.55$)$ & & $1.24(1.02$ to 1.51$)$ & \\
\hline $3-3.5$ & $2505(39.0)$ & 1 & & 1 & \\
\hline $3.5-4$ & $1818(28.3)$ & $0.94(0.74$ to 1.18$)$ & & $0.92(0.76$ to 1.10$)$ & \\
\hline$>4$ & $574(8.9)$ & $0.81(0.55$ to 1.18$)$ & & 0.75 (0.56 to 1.02$)$ & \\
\hline \multicolumn{6}{|l|}{ Paternal social class at birth } \\
\hline I & $381(5.9)$ & $1.60(1.09$ to 2.35$)$ & \multirow[t]{7}{*}{$0.007^{2}$} & $0.94(0.67$ to 1.33$)$ & \multirow[t]{7}{*}{$0.979^{2}$} \\
\hline II & 859 913.4) & $1.21(0.91$ to 1.61$)$ & & $0.93(0.73$ to 1.18$)$ & \\
\hline III NM & $923(14.4)$ & $1.12(0.85$ to 1.49$)$ & & $1.05(0.84$ to 1.31$)$ & \\
\hline III M (baseline) & $2839(44.2)$ & 1 & & 1 & \\
\hline IV & $824(12.8)$ & $0.93(0.68$ to 1.26$)$ & & $0.85(0.67$ to 1.07$)$ & \\
\hline $\mathrm{V}$ & $272(4.2)$ & $0.95(0.58$ to 1.57$)$ & & $1.16(0.82$ to 1.64$)$ & \\
\hline Other & $322(5.0)$ & 1.60 (1.11 to 2.32$)$ & & $1.13(0.82$ to 1.56$)$ & \\
\hline \multicolumn{6}{|c|}{ Older children in house, age 5} \\
\hline None & $2637(41.1)$ & 1 & \multirow[t]{4}{*}{0.034} & 1 & 0.749 \\
\hline 1 & $2287935.6)$ & $0.82(0.65$ to 1.04$)$ & & $0.96(0.80$ to 1.16$)$ & \\
\hline 2 & $961(15.0)$ & $0.67(0.49$ to 0.93$)$ & & $0.96(0.76$ to 1.22$)$ & \\
\hline$>2$ & $535(8.3)$ & $0.79(0.54$ to 1.16$)$ & & $0.97(0.72$ to 1.29$)$ & \\
\hline Younger children in the ho & & & & & \\
\hline None & $3610(56.2)$ & 1 & 0.757 & 1 & 0.277 \\
\hline 1 & $2480(38.6)$ & $1.02(0.83$ to 1.27$)$ & & $0.99(0.84$ to 1.18$)$ & \\
\hline$>1$ & $330(5.1)$ & $0.85(0.55$ to 1.33$)$ & & $0.73(0.51$ to 1.06$)$ & \\
\hline Highest qualification at 26 & & & & & \\
\hline None & $345(5.4)$ & $0.70(0.41$ to 1.17$)$ & 0.876 & $1.01(0.72$ to 1.43$)$ & 0.526 \\
\hline CSE/NVQ1 & $1108(17.3)$ & 1 & & 1 & \\
\hline $\mathrm{O} / \mathrm{NVQ}_{2}$ & $2682(41.8)$ & $0.94(0.72$ to 1.22$)$ & & $1.04(0.84$ to 1.28$)$ & \\
\hline A/Higher & $966(15.0)$ & $1.03(0.75$ to 1.41$)$ & & $1.10(0.85$ to 1.42$)$ & \\
\hline Degree & $1319(20.5)$ & $0.89(0.65$ to 1.23$)$ & & $1.07(0.83$ to 1.40$)$ & \\
\hline Smoking at 26 & & & & & \\
\hline Never & $3126(48.7)$ & 1 & 0.496 & 1 & $<0.001$ \\
\hline Ex & $1001(15.6)$ & $1.17(0.91$ to 1.50$)$ & & $1.08(0.84$ to 1.28$)$ & \\
\hline Current ( $<10$ cigs/day) & $898(14.0)$ & $0.92(0.69$ to 1.23$)$ & & $1.49(1.19$ to 1.86$)$ & \\
\hline Current ( $\geqslant 10$ cigs/day) & $1395(21.7)$ & $0.93(0.73$ to 1.20$)$ & & 2.35 (1.96 to 2.82$)$ & \\
\hline Quintile of height at 26 & & & & & \\
\hline 1 & $1357(21.1)$ & 1 & 0.214 & 1 & 0.442 \\
\hline 2 & $1651(25.7)$ & $1.03(0.80$ to 1.34$)$ & & $1.04(0.84$ to 1.28$)$ & \\
\hline 3 & $1343(20.9)$ & $1.03(0.78$ to 1.36$)$ & & $1.06(0.84$ to 1.32$)$ & \\
\hline 4 & $1008(15.7)$ & $0.90(0.65$ to 1.23$)$ & & $0.96(0.75$ to 1.24$)$ & \\
\hline 5 & $1061(16.5)$ & $0.85(0.62$ to 1.17$)$ & & $1.15(0.90$ to 1.47$)$ & \\
\hline Quintile of BMI at 26 & & & & & \\
\hline 1 & $1340(20.9)$ & 1 & $<0.001$ & 1 & 0.001 \\
\hline 2 & $1298(20.2)$ & $1.02(0.75$ to 1.38$)$ & & $1.02(0.81$ to 1.29$)$ & \\
\hline 3 & $1241(19.3)$ & $1.18(0.88$ to 1.60$)$ & & $0.94(0.74$ to 1.20$)$ & \\
\hline 4 & $1317(20.5)$ & $1.17(0.87$ to 1.58$)$ & & $1.13(0.90$ to 1.42$)$ & \\
\hline 5 & $1224(19.1)$ & $1.72(1.29$ to 2.29$)$ & & $1.44(1.15$ to 1.81$)$ & \\
\hline
\end{tabular}

${ }^{1}$ Test for trend.

${ }^{2}$ Excluding "other" group. 
Table 3 Association of hayfever and eczema in the previous 12 months at 26 years with early life risk factors and adult characteristics. Odds ratios are controlled for other factors in the table

\begin{tabular}{|c|c|c|c|c|}
\hline & \multicolumn{2}{|l|}{ Hayfever } & \multicolumn{2}{|l|}{ Eczema } \\
\hline & OR $(95 \% C I)$ & $p^{1}$ & OR $(95 \% C I)$ & $p^{1}$ \\
\hline \multicolumn{5}{|l|}{ Sex } \\
\hline M & 1 & \multirow[t]{2}{*}{0.537} & 1 & \multirow[t]{2}{*}{$<0.001$} \\
\hline $\mathrm{F}$ & $0.96(0.85$ to 1.09$)$ & & 1.89 (1.60 to 2.23$)$ & \\
\hline \multicolumn{5}{|c|}{ Maternal smoking in pregnancy } \\
\hline No & 1 & \multirow[t]{6}{*}{0.178} & 1 & \multirow[t]{6}{*}{0.235} \\
\hline Stopped prior & $0.87(0.72$ to 1.05$)$ & & $1.12(0.89$ to 1.40$)$ & \\
\hline Stopped during & $0.97(0.73$ to 1.30$)$ & & $0.95(0.66$ to 1.37$)$ & \\
\hline$<5 /$ day & $1.02(0.80$ to 1.29$)$ & & $1.05(0.78$ to 1.42$)$ & \\
\hline $5-14 /$ day & $0.94(0.80$ to 1.12$)$ & & $0.91(0.73$ to 1.13$)$ & \\
\hline$\geqslant 15 /$ day & $0.80(0.64$ to 1.00$)$ & & $0.87(0.66$ to 1.15$)$ & \\
\hline \multicolumn{5}{|l|}{ Birth weight $(\mathrm{kg})$} \\
\hline$<2$ & $1.39(0.79$ to 2.45$)$ & \multirow[t]{6}{*}{0.155} & $1.12(0.54$ to 2.31$)$ & \multirow[t]{6}{*}{0.459} \\
\hline $2-2.5$ & $0.79(0.56$ to 1.12$)$ & & $0.82(0.53$ to 1.26$)$ & \\
\hline $2.5-3$ & $1.09(0.92$ to 1.29$)$ & & $0.99(0.80$ to 1.22$)$ & \\
\hline $3-3.5$ & 1 & & 1 & \\
\hline $3.5-4$ & $1.09(0.94$ to 1.27$)$ & & $0.79(0.65$ to 0.96$)$ & \\
\hline$>4$ & $1.26(1.01$ to 1.57$)$ & & $1.05(0.79$ to 1.38$)$ & \\
\hline \multicolumn{5}{|l|}{ Paternal social class at birth } \\
\hline I & $1.13(0.87$ to 1.47$)$ & \multirow[t]{7}{*}{$0.207^{2}$} & $1.08(0.78$ to 1.51$)$ & \multirow[t]{7}{*}{$0.232^{2}$} \\
\hline II & $1.00(0.83$ to 1.21$)$ & & $0.99(0.78$ to 1.25$)$ & \\
\hline III NM & $1.19(0.99$ to 1.42$)$ & & $0.95(0.76$ to 1.20$)$ & \\
\hline III M (baseline) & 1 & & 1 & \\
\hline IV & $0.99(0.81$ to 1.21$)$ & & $0.95(0.74$ to 1.22$)$ & \\
\hline $\mathrm{V}$ & $0.91(0.65$ to 1.27$)$ & & $0.62(0.38$ to 1.00$)$ & \\
\hline Other & $1.41(1.08$ to 1.84$)$ & & $1.00(0.70$ to 1.43$)$ & \\
\hline \multicolumn{5}{|c|}{ Older children in house, age 5} \\
\hline None & 1 & \multirow[t]{4}{*}{$<0.001$} & 1 & \multirow{4}{*}{0.517} \\
\hline 1 & $0.72(0.61$ to 0.84$)$ & & $1.05(0.86$ to 1.28$)$ & \\
\hline 2 & $0.66(0.54$ to 0.81$)$ & & $0.96(0.75$ to 1.24$)$ & \\
\hline$>2$ & $0.66(0.51$ to 0.85$)$ & & $1.18(0.88$ to 1.59$)$ & \\
\hline Younger children in the ho & & & & \\
\hline None & 1 & 0.011 & 1 & 0.013 \\
\hline 1 & $0.83(0.71$ to 0.95$)$ & & $0.89(0.75$ to 1.07$)$ & \\
\hline$>1$ & $0.80(0.60$ to 1.07$)$ & & $0.53(0.34$ to 0.83$)$ & \\
\hline Highest qualification at 26 & & & & \\
\hline None & $0.92(0.65$ to 1.31$)$ & 0.001 & $0.67(0.43$ to 1.05$)$ & 0.010 \\
\hline CSE/NVQ1 & 1 & & 1 & \\
\hline $\mathrm{O} / \mathrm{NVQ} 2$ & $1.42(1.18$ to 1.72$)$ & & $1.08(0.87$ to 1.36$)$ & \\
\hline A/Higher & $1.42(1.14$ to 1.78$)$ & & $1.17(0.89$ to 1.54$)$ & \\
\hline Degree & $1.46(1.17$ to 1.82$)$ & & $1.26(0.96$ to 1.65$)$ & \\
\hline Smoking at 26 & & & & \\
\hline Never & 1 & 0.002 & 1 & 0.008 \\
\hline Ex & $1.06(0.90$ to 1.26$)$ & & $1.32(1.06$ to 1.63$)$ & \\
\hline Current (<10 cigs/day) & $0.91(0.75$ to 1.09$)$ & & $1.14(0.90$ to 1.44$)$ & \\
\hline Current ( $\geqslant 10$ cigs/day) & $0.76(0.65$ to 0.91$)$ & & $1.33(1.08$ to 1.63$)$ & \\
\hline Quintile of height at 26 & & & & \\
\hline 1 & 1 & 0.524 & 1 & 0.846 \\
\hline 2 & $0.98(0.82$ to 1.18$)$ & & $0.91(0.72$ to 1.14$)$ & \\
\hline 3 & $1.11(0.92$ to 1.34$)$ & & $1.08(0.86$ to 1.37$)$ & \\
\hline 4 & $0.98(0.79$ to 1.20$)$ & & $1.07(0.82$ to 1.39$)$ & \\
\hline 5 & $0.92(0.75$ to 1.13$)$ & & $0.88(0.68$ to 1.15$)$ & \\
\hline Quintile of BMI at 26 & & & & \\
\hline 1 & 1 & 0.101 & 1 & 0.293 \\
\hline 2 & $1.07(0.89$ to 1.30$)$ & & $1.04(0.82$ to 1.32$)$ & \\
\hline 3 & $0.99(0.81$ to 1.20$)$ & & $0.94(0.73$ to 1.20$)$ & \\
\hline 4 & $1.15(0.95$ to 1.40$)$ & & $1.17(0.93$ to 1.48$)$ & \\
\hline 5 & $1.16(0.95$ to 1.41$)$ & & $1.09(0.85$ to 1.39$)$ & \\
\hline
\end{tabular}

${ }^{1}$ Test for trend.

${ }^{2}$ Excluding "other" group.

potential confounding factors in the regression models.

Table 4 shows the association between adult BMI (in quintiles and classified according to "normal weight", "overweight" and "obese") and asthma in men and women, after controlling

Table 4 Association of BMI and asthma at age 26 years in men and women, controlling for other factors

\begin{tabular}{lll}
\hline & $\begin{array}{l}\text { Men } \\
\text { OR }(95 \% C I)\end{array}$ & $\begin{array}{l}\text { Women } \\
\text { OR }(95 \% C I)\end{array}$ \\
\hline $\begin{array}{l}\text { Quintile of BMI at 26 } \\
1\end{array}$ & 1 & 1 \\
2 & $0.91(0.57$ to 1.46$)$ & $1.07(0.71$ to 1.60$)$ \\
3 & $1.01(0.63$ to 1.61$)$ & $1.31(0.88$ to 1.96$)$ \\
4 & $0.77(0.48$ to 1.24$)$ & $1.49(1.01$ to 2.20$)$ \\
5 & $1.39(0.89$ to 2.17$)$ & $2.00(1.36$ to 2.94$)$ \\
$\begin{array}{l}\text { Standard classification of BMI } \\
<25\end{array}$ & 1 & 1 \\
$25-29.99$ (overweight) & $1.13(0.82$ to 1.56$)$ & $1.51(1.11$ to 2.06$)$ \\
$\geqslant 30$ (obese) & $1.43(0.82$ to 2.50$)$ & $1.84(1.19$ to 2.84$)$ \\
\hline
\end{tabular}

for other factors in table 2. This shows that the association was stronger in women although there was no clear evidence for an interaction between sex and BMI ( $p=0.19)$. In women a graded relation was seen across the whole distribution of BMI, with a twofold higher prevalence of asthma in individuals in the highest quintile than in those in the lowest quintile.

There were no significant interactions between BMI and birth weight, parental anthropometry, adult smoking, or family history of atopy on asthma. The association between BMI and wheeze was present in never smokers (OR per quintile 1.14 (95\% CI 1.05 to 1.25 )) but not in ever smokers (OR 1.02 (95\% CI 0.95 to 1.10$) ; \mathrm{p}$ for interaction 0.053$)$. A strong association between BMI and wheeze in never smokers remained in individuals who did not report a diagnosis of asthma. 
BMI at 10 years was not associated with asthma or wheeze at 26 years of age. There was no significant difference in mean BMI at 26 years between individuals with and without "asthma/wheeze" at 10 years (mean difference $0.15(95 \% \mathrm{CI}-0.17$ to 0.47$) ; \mathrm{p}=0.36)$.

\section{Discussion}

We have shown that a lower birth weight and a higher BMI in adult life were associated with a higher prevalence of asthma and wheeze among individuals in a national birth cohort studied at 26 years of age. The association with $\mathrm{BMI}$ was stronger in women.

The association with lower birth weight, after controlling for gestational age, suggests that impaired fetal growth is a determinant of adult asthma. In older adults lower birth weight is associated with lower lung function, a relation which is likely to be explained by impaired fetal airway growth leading to suboptimal airway calibre in adult life. ${ }^{29}$ We believe that small airway size is also likely to explain the association between lower birth weight and asthma. It seems plausible that, for a given degree of atopy and bronchial hyperreactivity, a young adult with smaller airways would be more likely to experience asthma symptoms. It seems less likely that the association between lower birth weight and asthma is explained by a higher prevalence of atopy. Lower birth weight was not associated with a higher prevalence of hayfever which is in keeping with findings for adult hayfever and atopy in another British national birth cohort. ${ }^{30}{ }^{31}$ In fact, the prevalence of hayfever was higher in individuals in the highest birth weight group than in those in the modal group, which is consistent with findings for allergic rhinitis in a large study of male conscripts. ${ }^{8}$ This suggests that faster rates of fetal growth may be a risk factor for atopy. Birth weight is a crude marker of fetal growth and measures of body proportion at birth may be more sensitive indicators of impaired prenatal growth during critical periods of immunological and pulmonary development. For example, a large head circumference at birth was associated with elevated total IgE in adults ${ }^{32}$ and a higher prevalence of asthma in children. ${ }^{5}$ We had no information on birth measurements other than weight in our study, although information on head circumference at 10 years was available. This measure, although likely to be highly correlated with head circumference at birth, was unrelated to atopic disease at 26 years (data not shown).

There are few published data on the relation between fatness and asthma in young adults. Surveys of mainly older adults have reported an association between obesity (defined as a BMI of >30) and asthma which was only present ${ }^{18}$ or was stronger ${ }^{19}$ in women. Our findings are in keeping with this, but we found that the association between BMI and asthma in women was graded across the whole distribution of BMI. Previous studies have found that fatter individuals are also more likely to report a history of chronic obstructive pulmonary disease ${ }^{19}$ and symptoms such as wheeze, waking at night with shortness of breath, chronic bronchitis, and shortness of breath on exertion. ${ }^{33}$ We have found clearer evidence for a relation between fatness and asthma than smoking related airflow obstruction, as we were studying young adults, and a positive association between BMI and wheeze was present in never smokers.

We think it unlikely that the association between BMI and asthma resulted from non-response. If this were so, then higher BMI values would have to be associated with a lower prevalence of asthma and wheeze in nonresponders. We have no reason to believe that BMI, which was calculated from reported height and weight, would be preferentially overestimated in asthmatic individuals. In general, self-reporting of height and weight leads to an underestimate of BMI. ${ }^{35}$ This happens more in fat people, which could therefore lead to underestimation of the association between BMI and asthma.

Is asthma diagnosed more in fatter than in thinner individuals? A study of adolescents found the opposite, with asthma being underdiagnosed in obese individuals. ${ }^{36}$ Furthermore, we found that a strong association between $\mathrm{BMI}$ and reported wheeze was present in never smokers, even in those who did not report a diagnosis of asthma. Obese adults may experience shortness of breath on exertion through lack of fitness. However, we are not aware that this symptom is perceived by fat individuals as wheeze, nor that this would occur more in women than in men. Similarly, we have no reason to believe that asthma and wheeze are more likely to be reported by fatter individuals.

The association between BMI and asthma and wheeze persisted on controlling for potential confounding factors. However, it might be explained by factors which were not measured. Firstly, a low level of physical activity is clearly associated with higher BMI and has also been proposed as a risk factor for asthma. PlattsMills and colleagues have suggested that reductions in deep breathing associated with a sedentary lifestyle may, by reducing the extent to which bronchial muscle is stretched, lead to airway narrowing. ${ }^{37}$ Prospective data linking level of physical activity to risk of asthma in young adults are lacking and cross sectional data are conflicting. Whilst a British survey of older adults found that wheezing was more common in individuals with low levels of physical activity, ${ }^{33}$ another survey found no association between level of physical activity and attacks of wheezing in young adults aged 16-44. ${ }^{11}$ Secondly, the association between BMI and asthma and wheeze might be explained by dietary factors. For example, a low intake of antioxidants, which has been proposed as a risk factor for asthma, ${ }^{38}$ may be more common in obese than in non-obese subjects.

Does asthma cause fatness? The association between adult BMI and asthma was cross sectional. One possible interpretation is that a higher BMI is a consequence of asthma; weight gain could occur as a side effect of oral corticosteroid therapy or because asthmatic individuals avoid vigorous physical activity in order to prevent exercise induced bronchospasm. 
However, only a very small proportion of adults with asthma take regular oral steroids and, in a study of young adults in South London, we have found that the frequency of participation in regular vigorous sporting activity was similar in those with and without asthma (authors' unpublished observations, 1998). Furthermore, individuals with asthma or wheeze at 10 years were not significantly fatter at 26 years.

Does fatness cause asthma? The graded association between BMI and asthma in women is consistent with a causal effect. We propose that fatness may increase the severity of asthma in those with established disease and may increase prevalence by contributing to symptoms in individuals who would otherwise have subclinical disease. If it is concurrent fatness which increases risk of asthma, then it is perhaps not surprising that BMI at 10 years was not associated with adult asthma, since the majority of obese adults would not have been obese as children. Is it possible that there is a direct mechanism linking fatness to asthma in adults? The stronger findings in women may be relevant. Oestrogens have been implicated as a risk factor for adult asthma ${ }^{39}$ and might contribute in part to the higher prevalence of asthma and wheeze in women. We speculate that oestrogenic effects on asthma might be enhanced in fatter women because obesity is associated with higher levels of bioavailable oestrogen in premenopausal women. ${ }^{40}$ Furthermore, smoking is thought to have antioestrogenic effects ${ }^{41}$ which might explain why a strong positive association between BMI and wheeze was observed in never smokers but not in smokers.

Alternatively, the sex difference may be explained by the fact that BMI is not a comparable measure of fatness in men and women. For an equivalent BMI women have significantly greater amounts of total body fat than men. ${ }^{42}$ The lack of an association between BMI and hayfever and eczema is in keeping with a previous survey ${ }^{19}$ and suggests that fatness is not a risk factor for atopy.

New hypotheses are urgently needed to explain the rise in asthma in developed countries so that preventive strategies can be devised. The prevalence of overweight and obesity continues to rise in countries such as Britain. How might the nature of the association between BMI and asthma in adults be clarified? It would be of interest to see whether $\mathrm{BMI}$ is associated with an objective measure of asthma such as bronchial hyperreactivity, and to determine whether dietary factors might account for such a link. Continued follow up of this or other cohorts may establish whether raised BMI, or an increase in BMI, predates the onset of asthma. However, such an association would be difficult to detect if the onset of asthma is close in time to an increase in BMI. An alternative approach, particularly in view of recent findings in children, ${ }^{17}$ would be to conduct a controlled trial of weight reduction in adults with asthma to examine the impact on the presence and severity of disease.
The authors would like to thank the Centre for Longitudinal Studies, Institute of Education for their assistance with tracing the cohort and enabling them to access the data, and Dr Roberto Rona for helpful discussion and comments on an earlier draft of this paper. SOS, JACS and HA are funded by the UK Department of Health. SMM is supported by the Hayward Foundation.

1 Shaheen S. Discovering the causes of atopy. BMF 1997;314:987-8

2 Schwartz J, Gold D, Dockery DW, et al. Predictors of asthma and persistent wheeze in a national sample of children in the United States. Association with social class, perinatal events, and race. Am Rev Respir Dis 1990;142: 555-62.

3 Weitzman M, Gortmaker S, Sobol A. Racial, social, and environmental risks for childhood asthma. Am $\mathcal{F}$ Dis Child 1990;144:1189-94.

4 Sears MR, Holdaway MD, Flannery EM, et al. Parental and neonatal risk factors for atopy, airway hyperneonatal risk factors for atopy, airway hyper-
responsiveness, and asthma. Arch Dis Child 1996;75:392-8.

5 Fergusson DM, Crane J, Beasley R, et al. Perinatal factors and atopic disease in childhood. Clin Exp Allergy 1997;27: 1394-401.

6 Kelly YJ, Brabin BJ, Milligan P, et al. Maternal asthma, premature birth, and the risk of respiratory morbidity in schoolchildren in Merseyside. Thorax 1995;50:525-30.

7 Demissie K, Ernst P, Joseph L, et al. Birthweight and preterm birth in relation to indicators of childhood asthma. Can Respir f 1997;4:91-7.

8 Braback L, Hedberg A. Perinatal risk factors for atopic disease in conscripts. Clin Exp Allergy 1998;28:936-42.

9 Seidman DS, Laor A, Gale R, et al. Is low birth weight a risk factor for asthma during adolescence? Arch Dis Child 1991; 66:584-7.

10 Fleming DM, Crombie DL. Prevalence of asthma and hay fever in England and Wales. BMF 1987;294:279-83.

11 Bennett N, Dodd T, Flatley J, et al. The health survey for England 1993. London: HMSO, 1995.

12 Rosenbaum S, Skinner RK, Knight IB, et al. A survey of heights and weights of adults in Great Britain, 1980. Ann Hum Biol 1985;12:115-27.

13 Gregory J, Foster K, Tyler $\mathrm{H}$, et al. The dietary and nutritional survey of British adults. London: Social Survey Division, Office of Population Censuses and Surveys, HMSO, 1990.

14 Burney PG, Chinn S, Rona RJ. Has the prevalence of asthma increased in children? Evidence from the national study of health and growth 1973-86. BMf 1990;300:130610 .

15 Chinn S, Rona RJ. Trends in weight-for-height and triceps skinfold thickness for English and Scottish children, 19721982 and 1982-1990. Paediatr Perinat Epidemiol 1994;8: 1982 and 1

16 Gold DR, Rotnitzky A, Damokosh AI, et al. Race and gender differences in respiratory illness prevalence and their relationship to environmental exposures in children 7 to 14 years of age. Am Rev Respir Dis 1993;148:10-18.

17 Luder E, Melnik TA, DiMaio M. Association of being overweight with greater asthma symptoms in inner city black and Hispanic children. $\mathcal{F}$ Pediatr 1998;132:699-703.

18 Seidell JC, de Groot LC, van Sonsbeek JL, et al. Associations of moderate and severe overweight with self-reported illness and medical care in Dutch adults. Am 7 Public Health 1986;76:264-9.

19 Negri E, Pagano R, Decarli A, et al. Body weight and the prevalence of chronic diseases. $\mathcal{F}$ Epidemiol Community Health 1988;42:24-9.

20 Butler NR, Golding J. Introduction. In: From birth to five. A study of the health and behaviour of Britain's five-year-olds. Oxford: Pergamon Press, 1986:1-7.

21 Ekinsmyth C, Bynner JM, Montgomery SM, et al. An integrated approach to the design and analysis of the 1970 British Cohort Study (BCS70) and the National Child Development Study (NCDS). Inter-cohort analysis working paper 1. London: City University Social Statistics Research Unit (SSRU), 1993.

22 Shepherd P. Survey and response. In: Bynner JM, Ferri E, Shepherd P, eds. Twenty-something in the 1990s. Aldershot: Ashgate Press, 1997: 130-6.

23 Garrow JS. Obesity and related diseases. London: Churchill Livingstone, 1988.

24 Lewis S, Butland B, Strachan D, et al. Study of the aetiology of wheezing illness at age 16 in two national British birth of wheezing illness at age 16 in th

25 Butland BK, Strachan DP, Lewis S, et al. Investigation into the increase in hay fever and eczema at age 16 observed between the 1958 and 1970 British birth cohorts. BMF 1997;315:717-21

26 Registrar General of England and Wales. Classification of occupations. London: HMSO, 1966.

27 Leon DA, Koupilova I, Lithell HO, et al. Failure to realise growth potential in utero and adult obesity in relation to blood pressure in 50 year old Swedish men BMF 1996;312: 401-6.

28 Michels KB, Greenland S, Rosner BA. Does body mass index adequately capture the relation of body composition and body size to health outcomes? Am $\mathcal{f}$ Epidemiol 1998;147:167-72.

29 Shaheen S. The beginnings of chronic airflow obstruction. Br Med Bull 1997;53:58-70.

30 Strachan DP. Epidemiology of hay fever: towards a community diagnosis. Clin Exp Allergy 1995;25:296-303. 
31 Strachan DP, Harkins LS, Johnston ID, et al. Childhood antecedents of allergic sensitization in young British adults. antecedents of allergic sensitization in
7 Allergy Clin Immunol 1997;99:6-12.

32 Godfrey KM, Barker DJ, Osmond C. Disproportionate fetal growth and raised IgE concentration in adult life. Clin Exp Allergy 1994;24:641-8.

33 Dean G, Lee PN, Todd GF, et al. Factors related to respiratory and cardiovascular symptoms in the United Kingdom. 7 Epidemiol Community Health 1978;32:86-96.

34 Lean ME, Han TS, Seidell JC. Impairment of health and quality of life in people with large waist circumference. Lancet 1998;351:853-6.

35 Stewart AW, Jackson RT, Ford MA, et al. Underestimation of relative weight by use of self-reported height and weight. Am 7 Epidemiol 1987;125:122-6.

36 Siersted HC, Boldsen J, Hansen HS, et al. Population based study of risk factors for underdiagnosis of asthma in adolescence: Odense schoolchild study. BMF 1998;316: $651-5$.
37 Platts-Mills TAE, Sporik RB, Chapman MD, et al. The role of domestic allergens. Ciba Foundation Symposium 1997;

38 Seaton A, Godden DJ, Brown K. Increase in asthma: a more toxic environment or a more susceptible population? Thorax 1994;49:171-4.

39 Troisi RJ, Speizer FE, Willett WC, et al. Menopause, postmenopausal estrogen preparations, and the risk of adult-onset asthma. A prospective cohort study. $A m \mathcal{F}$ Respir Crit Care Med 1995;152:1183-8.

40 Ingram $\mathrm{D}$, Nottage $\mathrm{E}, \mathrm{Ng} \mathrm{S}$, et al. Obesity and breast disease. The role of the female sex hormones. Cancer 1989; 64:1049-53.

41 Brunet S-G, Ghadirian P, Rebbeck TR, et al. Effect of smoking on breast cancer in carriers of mutant $B R C A 1$ or BRCA2 genes. 7 Natl Cancer Inst 1998;90:761-6.

42 Gallagher D, Visser M, Sepulveda D, et al. How useful is body mass index for comparison of body fatness across age, sex, and ethnic groups? Am f Epidemiol 1996;143:228-39. 